\title{
A inserção da arte nas revitalizações urbanas
}

\author{
The Insertion of Art in Urban Revitalizations
}

\section{La inserción del arte en las revitalizaciones urbanas}

$\begin{array}{r}\text { Marilane Abreu Santos * }^{*} \\ \hline \text { http://dx.doi.org/10.22409/poiesis.1931.81-98 }\end{array}$

RESUMO: Um conjunto de trabalhos artísticos foi produzido no interior de uma antiga fábrica em desuso. As obras trazem à tona temas vinculados aos processos de revitalização urbana, iluminando conflitos e ambiguidades replicadas em nível local e mundial, colocando em questão o papel da arte em meio aos modelos de cidade na contemporaneidade.

PALAVRAS-CHAVE: arte; cidade; política

\footnotetext{
* Marilane Abreu Santos é Doutora em Arte e Cultura Contemporânea pelo Programa de Pós-Graduação em Artes da Universidade do Estado do Rio de Janeiro. Atualmente é professora de Artes Visuais do Colégio de Aplicação da UFRJ. E-mail: mari.abreu.santos@gmail.com
} 
ABSTRACT: A set of artworks was produced inside an old factory in disuse. The works bring to the fore themes related to the processes of urban revitalization, illuminating conflicts and ambiguities replicated at the local and global level, calling into question the role of art in the midst of contemporary city models.

KEYWORDS: art; city; politics

RESUMEN: Un conjunto de trabajos artísticos fue producido en el interior de una antigua fábrica en desuso. Las obras traen temas vinculados a los procesos de revitalización urbana, alumbrando conflictos y ambiguedades replicadas a nivel local y global, poniendo en cuestión el papel del arte en medio a los modelos de ciudad en la contemporaneidad.

PALABRAS CLAVE: arte; ciudad; política 


\section{A inserção da arte nas revitalizações urbanas}

\section{Revitalizações urbanas e a fabriquização da cidade}

Os processos de remodelação urbana já não são mais novidade nos dias atuais. Os novos traçados urbanos e as "inovadoras" propostas de reorganização das cidades passaram a inserir a arte e a cultura como mote de sua estrutura através da "cidade criativa"1, conceito desenvolvido pelo inglês Charles Landry. Tendo como dispositivo a criatividade, propõem-se a inovação, o uso inteligente da tecnologia, a tolerância e o talento para inserir em locais apontados como "abandonados" e "perigosos" novas propostas de ocupação que favoreceriam a população, promovendo o desenvolvimento econômico e social. Diversas cidades pelo mundo vivenciam essas transformações e, cotidianamente, vê-se replicar modelos de urbanização que seguem um receituário neoliberal. No Rio de Janeiro não foi diferente. Os grandes eventos esportivos de 2014 e 2016 aceleraram esse processo e aqui, como em outros lugares, a população ainda sente seus reflexos. É desnecessário enumerar todos os impactos de fundo econômico e social, pois ainda os sentimos na alta dos preços, reflexo da supervalorização do solo e especulação imobiliária, além de vermos exacerbar a intolerância e a violência, fruto das políticas de segregação agravadas pela profunda desigualdade social que vivemos. 
Barcelona ficou conhecida como "la mayor tienda del mundo" e serviu de modelo para diversos projetos, inclusive o do Rio. Revisitada dez anos depois das transformações, foi alvo de severas críticas e, mesmo assim, inspirou a concepção do Porto Maravilha. O arquiteto e urbanista espanhol Manuel Delgado a considera uma cidade-marketing e afirma que a cidade se tornou um

modelo ou protótipo de cidadefábrica urbe convertida em enorme cadeia de produção de sonhos e simulacros, que faz de sua própria mentira sua principal indústria e que faz de seu componente humano um exército de trabalhadores-prisioneiros, produtores e, ao mesmo tempo, vendedores de seu próprio nada. (DELGADO, 2007, p. 14, grifo nosso)

O uso da palavra fábrica é significativo por diversos motivos. De forma literal, em alguns desses projetos de requalificação urbana estão inseridos o reaproveitamento de espaços industriais em desuso. A globalização, a desindustrialização e a transferência da produção fabril para outros países contribuíram para o surgimento de grandes espaços vazios, os quais são reutilizados através da criação de centros culturais, por exemplo. De maneira simbólica, mas não menos estruturante, tais usos reorganizam a vida dessas cidades. $O$ arquiteto e professor Pier Vittorio Aureli contribui para a compreensão da fábrica como "dispositivo que liga trabalho à res extensa da valorização social", o que equivale defini-la como "dispositivo através do qual toda a sociedade é posta a trabalhar". O conceito de fábrica é tomado como "um paradigma para compreender a condição urbana contemporânea" e, segundo o autor, seu aparente desaparecimento "como ponto avançado do capitalismo no mundo desenvolvido tem sido muitas vezes interpretado como o puro e simples desaparecimento da classe trabalhadora", o que leva a uma visão da fábrica como um espaço fechado em si, específico da produção de bens materiais. Entretanto, em um sentindo mais amplo, tomada não como um edifício, mas como um "aparato, máquina ou artifício" que permite o controle do território e estendendo seus domínios sobre o social, a fábrica torna-se "indubitavelmente ligada ao território e desta maneira às formas de vida" (AURELI, 2016), mantendo e transformando suas estratégias de captura e apropriação.

Poiésis, Niterói, v. 19, n. 31, jan./jun. 2018. 
Na atualidade, com o avanço do capitalismo cognitivo e do trabalho imaterial2 ${ }^{2}$, há um "invisível" ou "dissimulado" processo de "frabiquização" que reativa a presença desse aparato com seus espaços abstratos, atuando no controle do trabalho e do trabalhador. Para Aureli, o "regresso da fábrica é assim uma provocação para redescobrir e reconstruir a geografia da fábrica contemporânea e sua relação simbiótica com a sociedade". Nos escritórios open floor das empresas ou no uso, cada vez mais disseminado pelo mundo, dos espaços industriais pela "classe criativa", toma-se o "trabalhador criativo" contemporâneo como modelo. Ele é empreendedor, livre e, ao mesmo tempo, precarizado e submetido 3 . Assim, de forma concreta os antigos espaços industriais em quase abandono nas cidades retomam suas formas arquitetônicas, reelaboram e ajudam a (re)distribuir a exploração do trabalho criativo (material e imaterial) pelo espaço urbano, reativando o controle e a apropriação, reinventando a fábrica. De acordo com Barbara Szaniecki:

Em tempos de capitalismo pós-industrial, o modelo das indústrias criativas não apenas soa anacrônico como aponta uma contradição: enquanto o termo "criativas" sugere a substituição da repetição industrial pela invenção sobre a qual se baseia a produção pós-industrial, o termo "indústrias" parecer insistir na redução do imprevisível à criação ao previsível de uma linha de montagem. E essa linha de montagem não se limita ao chão de fábrica, mas se estende a toda a metrópole, integrando produção e consumo. A tensão interna ao termo "indústrias criativas" aponta a esquizofrenia do capitalismo contemporâneo e a esquizofrenia dos nossos políticos (dos "vermelhos" aos "azuis" passando pelos "verdes"). [...] A linha de montagem da cidade criativa de hoje coincide perfeitamente com a linha de montagem da cidade industrial de outrora. (SZANIECKl; SILVA, 2010)

$\mathrm{Na}$ chamada cidade criativa, território organizado segundo planos econômicos que envolvem diretamente a cultura, a arte torna-se mote para o desenvolvimento. A busca e revitalização dos espaços ociosos nas cidades promovem um movimento diferente nos bairros levando até eles turistas, novos moradores e frequentadores de classes mais abastadas. A classe criativa, formada por designers, arquitetos, artistas, figurinistas e todas as categorias que trabalham diretamente com a arte e a cultura são cooptados para ocupar esses lugares. Muitas vezes, essa iniciativa parte do próprio grupo que, sozinho, chega a essas antigas indústrias em desuso. Entretanto, muitas dessas ocupações ${ }^{4}$ são negocia- 
das com o próprio governo e/ou com a iniciativa privada e aceleram o processo de gentrificação ${ }^{5}$, pois elas acontecem sem uma integração real com o bairro, sem um diálogo aberto com a população no intuito de atender às demandas e ajustar-se à realidade local. A arte assume um papel central nesse processo, pois articula a cultura aos modelos de remodelação urbana através de usos distintos.

Denominadas pelo professor da Universidad Autónoma de Madrid, Jesus Carrillo, como "fábricas da cultura", essas organizações estão inseridas no território urbano alterando o cotidiano, o ritmo de vida dos usuários das cidades. Segundo Carrillo, o início desse debate deve ser proposto a partir do uso que se fez do termo "cultura como recurso", cunhado por George Yudice e que reflete a noção hegemônica da cultura no chamado capitalismo pós-fordista. O fato de, na Espanha, dois discursos opostos - o neoliberal e o de esquerda - terem tomado como princípio comum essa concepção de cultura faz imaginar possíveis realidades díspares, em que uma inviabilizaria a outra. Assim, uma primeira situação se delineia, na qual a arte e a cultura seriam instrumentalizadas pelas instituições públicas e privadas com distintos fins que reforçariam a identidade local e europeia, o desenvolvimento regional, a criação de empregos no setor criativo, a previsão de atividades de "ócio populares" e dissuasão de qualquer questionamento ou conflito. Em uma outra situação, se teria o desenvolvimento de microssistemas culturais autônomos, críticos e comprometidos com a massa social. De um lado, temos um discurso de uma direita conservadora que propôs o "conglomerado heterogêneo e difuso de atividades pouco capitalizadas e dificilmente reguláveis, que era a cultura, como uma indústria autossuficiente e geradora de riqueza". (CARRILLO, 2012, p. 1) A transformação dessa noção burguesa de cultura em uma indústria cultural de projeção massiva foi contemporânea aos movimentos de privatização e mercantilização da cultura nos Estados Unidos e Inglaterra. De outro lado, o discurso crítico da esquerda abraça o mesmo pressuposto de que a cultura é antes de tudo um âmbito de produção de riqueza e no qual se define "um novo marco das relações sociais, trabalhistas e econômicas no mundo contemporâneo, constituindo por sua vez o horizonte de luta e de emancipação da nova era". Carrillo analisa que esse não seria o antagonismo entre cultura burguesa e proletária, mas um "debate sobre a titularidade, a gestão e as funções desse recurso". (CARRILLO, 2012, p. 2)

Poiésis, Niterói, v. 19, n. 31, jan./jun. 2018. 
O autor ainda aponta para os usos de certos termos notando que "produção" e "criação" são tomados como equivalentes e associados aos adjetivos "cultural" e "contemporâneo", criando, assim, um deslocamento da anteriormente "onipresente" e "autolegitimada" noção de arte. Segundo ele, neste cenário a "arte contemporânea" subsume na noção mais ampla de "cultura visual" aparecendo ao lado de outros, como a moda, o cinema et cétera. Todos identificados como setores de "produção". Neste contexto, a questão da originalidade da obra é colocada como problema para o meio produtivo, pois é "única" e, por isso, de difícil venda. Problema que facilmente encontra solução com a "produção" de peças em pequenos formatos como cinzeiros, camisetas e canecas que tenham enquanto referência o trabalho caro e original, mostrando uma visão limitada de arte de alguns defensores da economia criativa.

Inserida nessa linha de montagem, como se vê em muitos casos, a arte pode se amalgamar a esses processos auxiliando a espetacularização, mercantilização e turistificação da cidade. Por outro lado, pode fortalecer um caráter político inerente à sua prática e trazer à luz os meandros desses processos de captura e adesão docilizada. Diante da participação ambígua nas revitalizações urbanas, a arte pode assumir seu viés crítico iluminando e evidenciando questões, assumir seu caráter transgressor e de ruptura tão importante contra processos de massificação e homogeneização cultural.

\section{A arte e a reutilização de espaços industriais}

Um quadrado formado por vinte e cinco peças de azulejo, dos quais vinte e quatro são brancas e uma central que se parece com uma rosa dos ventos; um grande mosaico vertical em azulejos, com formas variadas e coloridas pintadas em suas superfícies e com alguns espaços vazios no meio; silhuetas femininas e suas sombras que, projetadas em uma parede, simulam um grande e lento balé em meio a um antigo maquinário; um vídeo projetado em uma janela velha no qual várias pessoas simulam uma fuga desta mesma janela; uma grande coluna de papel que imita ferro e apresenta seu interior carcomido pela ferrugem. O que vincula todas essas produções? Produzidas no interior de uma antiga fábrica de chocolates em desuso na região portuária do Rio de Janeiro, elas contam 
uma parte da história dessa indústria, em uma perspectiva mais local. Além disso, iluminam questões que relacionam a arte aos processos de revitalização urbana contemporâneos que ocorrem em nível mundial, replicando-se pelos diferentes centros urbanos ${ }^{6}$. Essas obras foram produzidas por diversos artistas em momentos distintos, em um período entre os anos de 2012 e 2016 . Evidenciaram diferentes conflitos internos vinculados aos interesses dos locatários e sua situação diante dos proprietários, do poder público e da sociedade, bem como apontaram para problemas externos, ligados aos atravessamentos políticos, sociais e econômicos inerentes aos processos de (re)modelação do Rio de Janeiro como "Cidade Criativa".

Na conexão Brasil-Espanha, guiada pelo modelo Barcelona criado em virtude de eventos esportivos de grande porte, o Rio de Janeiro encabeça a lista das "cidades criativas" brasileiras. No projeto de construção do Porto Maravilha, a Fábrica Bhering demorou um tempo até despertar o interesse do governo. Sua ocupação por artistas começou em 2006, mas somente em 2011 um leilão ativou o processo que explodiu em meados de 2012, quando a fábrica já estava ocupada por diversos locatários (ateliês de artistas e artesãos, pequenos comerciantes, sebo, café, restaurante, confecções, depósitos, dentre outros). Em meio a conflitos judiciais e promessas descumpridas do governo criou-se a Associação Civil de Economia Criativa Orestes 28 e, assim, os locatários conseguiram garantir sua permanência. Muitos holofotes passaram a iluminar os escuros corredores e amplos espaços da fábrica. O número de eventos, como Rio Design e ARTRio, assim como os eventos internos, foi ampliado e os andares da Bhering foram tomados por visitantes ávidos por frequentar um novo espaço "alternativo" da cidade. Junto às transformações do porto, com a criação de museus monumentos e marcos de futuro, inaugurou-se mais uma "fábrica da cultura" no mundo.

As indústrias criativas, distribuídas pelo território urbano, são empresas que exploram sem investir, pois não fornecem aos "criativos" "seus instrumentos, não paga(m) seus salários e não Ihes fornece proteção social". Segundo Barbara Szaniecki, o "modelo das indústrias criativas se baseia nessa forma de captura de uma produção que se dá sob o signo de intensa cooperação livre e num contexto de investimento capitalístico extremamen-

Poiésis, Niterói, v. 19, n. 31, jan./jun. 2018. 
te reduzido". (SZANIECKI, 2012, p. 42) Dificilmente será encontrada nas Indústrias Criativas a constituição de uma "esfera do comum", pois nelas o que é "produzido cooperativamente por muitos é sempre expropriado por forças externas a serviço dos interesses privados de poucos". (SZANIECKI, 2012, p. 42) Adaptada ao modelo neoliberal cada dia mais expandido, a Fábrica Bhering segue sua rotina reforçando e alimentando os descompassos do projeto de Porto Maravilha através de seus "eventos" pela cidade. Sem criar vínculos com seu entorno, a fabriquização estabelecida altera a vida e a rotina dos moradores e também a da cidade, levando um "público" novo às ruas do porto - o visitante consumidor encantado pelo brilho espetacularizado das vitrines.

Os trabalhos artísticos citados acima se apresentaram como pequenas obras-vagalumes ${ }^{7}$, trazendo à luz os conflitos existentes. Os trabalhos de Maíra das Neves, do Coletivo MUDA, de Sandra Macedo, de Elisa Pessoa e de Rodrigo Torres, apresentados acima nesta sequência, dialogaram com a fábrica em seu momento de transformação. Sem se adequar totalmente aos moldes espetacularizados das feiras e eventos, as produções artísticas apontaram para temas que se vinculavam não somente à estrutura da fábrica como um edifício antigo, mas como uma estrutura fabril, produtora de espaço em um território urbano que sofria mudanças. Retomando práticas artísticas dos anos 1960/70/80 - o site specific -, esse pequeno conjunto questionou os processos de gentrificação no Morro da Providência, o abandono das máquinas e da própria fábrica com sua estrutura precária, trazendo ao espaço a imagem-presença dos antigos operários esquecidos pelo tempo, evidenciou o trabalho do novo trabalhador e iluminou os conflitos internos e externos dessa indústria. Essas obras provocaram uma pequena fissura no conjunto maior e abriram espaço para levar adiante algumas discussões. Em diálogo com outras produções, avolumaram os questionamentos sobre processos na cidade maravilha.

Em seu pequeno ateliê-obra $1 \mathrm{~m} 2$ (Fig. 1), Maíra desenvolveu ações que tangenciavam outras práticas que se propõem a intervir em territórios, criando laços afetivos e simbólicos, questionadores e críticos em relação aos acontecidos na cidade. Em uma das atividades, criou uma oficina de estêncil e no Morro da Providência, juntamente com os moradores, estampou as fachadas das casas. A pintura-reposta ao SMH da prefeitura ${ }^{8}$, desenvol- 
vida conjuntamente com Mônica Nador do Jardim Miriam Arte Clube - JAMAC de SP, foi uma maneira de tentar construir com os moradores do Morro um espaço de convívio e de resistência em seu bairro, em suas próprias casas. Em sintonia com outras produções espalhadas pelo porto, fez ver que seria possível construir uma rede, produzindo outras formas de ocupar o porto, distintas daquelas coordenadas pelo projeto urbano. Seria preciso mais tempo. Não houve. Maira deixou a fábrica e seu metro quadrado encontra-se empoeirado no quinto andar.

O mosaico do Coletivo MUDA instalado no salão das máquinas apontou a precariedade e o abandono daquele lugar e trouxe também a possibilidade de recuperar a história daquelas máquinas enquanto havia vida e movimento. (Fig. 2) Como alguns dos painéis instalados pelo coletivo nas ruas de diversas cidades pelo mundo, também evidenciaram um abandono. Mesmo com seu pouco tempo de existência, a instalação possibilitou a construção de diálogos que mostram a indissociabilidade entre lembrança e esquecimento, além de reforçar que certas memórias são fundamentais. No contato com As desAparecidas, de Sandra Macedo (Fig. 3), que também ocupou o salão das máquinas, o mosaico contribuiu para reativar a história daquelas que faziam a fábrica se mover - as operárias. As antigas trabalhadoras da fábrica caíram no esquecimento até o momento, mas sua lembrança sobrevive através da Dona Aparecida, antiga funcionária homenageada, e do olhar sensível da artista.

Na eloquência de suas silhuetas instaladas em um velho motor de micro-ondas, no movimento leve e dançante, as operárias retornaram em meio às máquinas. Não se sabe sobre seu cotidiano, suas vidas, seus afetos e relações e tudo isso pairava no ar, com ânsia de ser atualizado. Sandra trouxe ao salão das máquinas algo a mais que poderia ser agregado ao desejo de criar o tão "suntuoso" Museu do Chocolate. A dura realidade do trabalho fabril se conecta à atualidade da precariedade do trabalho criativo, para muitos que se inserem no modelo de economia criativa. Em sintonia com a obra de Sandra, a videoinstalação Janela de Elisa Pessoa une passado e presente e coloca em diálogo o antigo e o novo, abrindo possibilidades de reflexões a respeito das novas formas de exploração do trabalho e o papel que o artista e sua arte têm nesse meio. Girando em um loop infinito,

Poiésis, Niterói, v. 19, n. 31, jan./jun. 2018. 


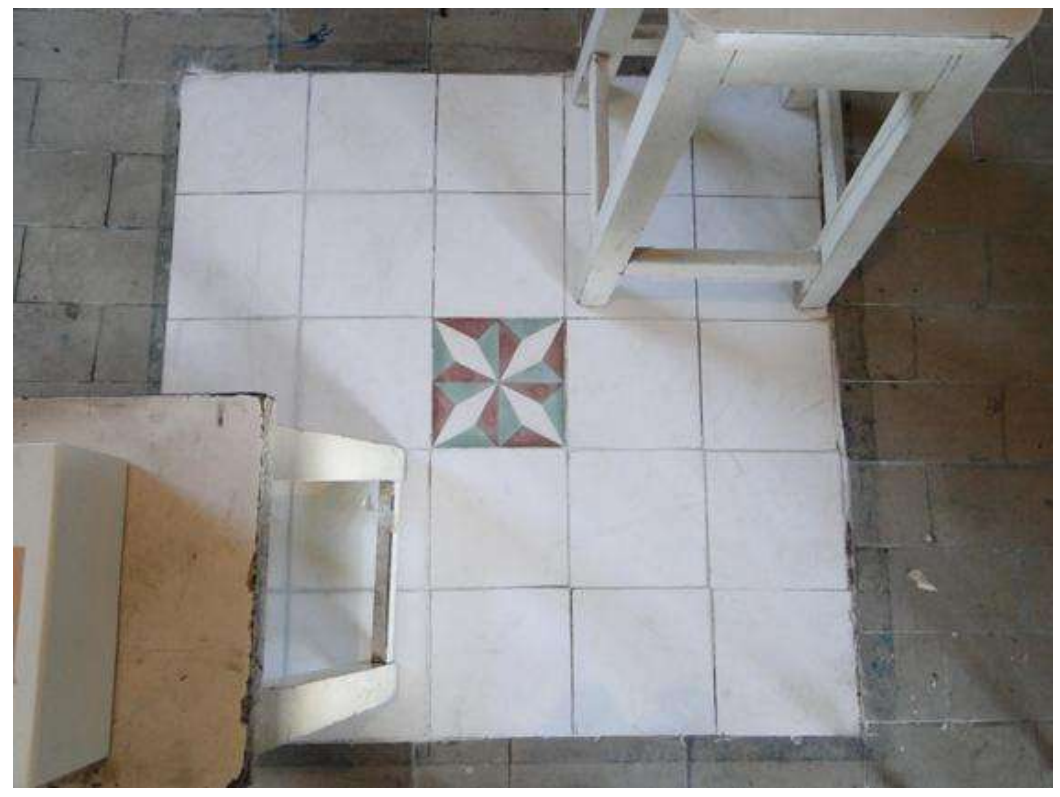

Fig. 1 - Maíra das Neves, 1m2, 2010/2013.

ateliê-obra $(1 \times 1 \mathrm{~m})$

(Fonte: www.mairadasneves.art.br/)

Poiésis, Niterói, v. 19, n. 31, jan./jun. 2018. 

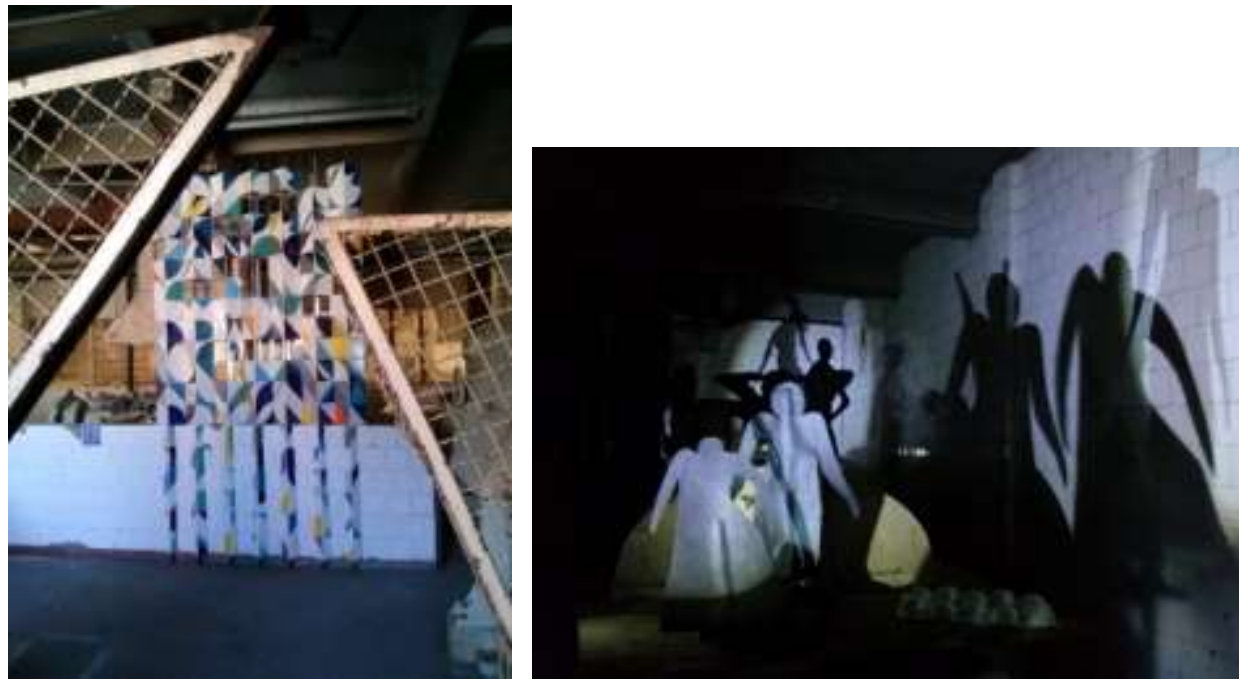

Fig. 2 - Coletivo MUDA, Instalação, 2014.

pintura sobre azulejo

(Fonte: foto da autora)

Fig. 3 - Sandra Macedo, As desAparecidas, 2014.

instalação

(Fonte: foto da autora)

Poiésis, Niterói, v. 19, n. 31, jan./jun. 2018. 
como as esteiras das antigas máquinas e as silhuetas de Sandra, os personagens pulam pela janela da fábrica de forma semelhante aos trabalhadores das indústrias registrados por Harum Faroki em sua obra Arbeiter verlassen die Fabrik. Entretanto, o retorno constante à cena lembra o gesto de um operador de máquina na indústria, sua rotina, o trabaIho mecanizado e repetitivo.

Por fim, a escultura Monumento Maravilha, de Rodrigo Torres (Fig. 4), rasgada e enferrujada, mostrou todo esse processo dentro e fora da Fábrica Bhering. Nome dado em referência ao Porto Maravilha, a obra desvelou as estruturas e os interesses políticos que se escondem por trás e por baixo de tanta poeira. Simbolicamente, as regras desse jogo ficam em evidência, mas não são claras porque, de fato, são feitas para permanecerem ocultadas. Marcada por sujeiras e imperfeições em sua pintura, a escultura-coluna, descartada após a exposição, era uma cópia das pilastras de sustentação da fábrica. Exposta pendurada por um fio de nylon, a obra reproduziu as ilusões e ambiguidades locais no oIhar do espectador. Trabalhando com o engano, Monumento Maravilha mostrou as dualidades que o artista quis colocar em diálogo: leveza/peso; papel/ferro; clareza/escuridão; pintura nova/ferrugem e que simbolicamente dialogam com outras: público/privado, memória/esquecimento, dentro/fora, processos/projetos, fábrica/cidade, passado/presente.

Como uma grande montagem, formando uma grande rede, as obras provocaram uma pequena fissura nessa estrutura e fizeram sua potência ecoar produzindo uma resistência crítica a todo o processo. Os nós dessa rede poderiam ser tramados com mais força através do contato com outras ações no porto e na cidade, mas a parte do tecido urbano que tece os fios do controle foi mais forte nesse processo. Apagadas após suas breves existências, os trabalhos artísticos sobrevivem nos registros, nas palavras e na memória de quem os viu.

Nas cidades revitalizadas, os projetos ligados à arte e à cultura se posicionam politicamente, fomentando processos no território de acordo com seus interesses. Na contemporaneidade, uma inserção mais consciente e crítica no espaço urbano convive com as formas espetacularizadas e "como" tudo acontece passa a definir os rumos de cada projeto.

Poiésis, Niterói, v. 19, n. 31, jan./jun. 2018. 


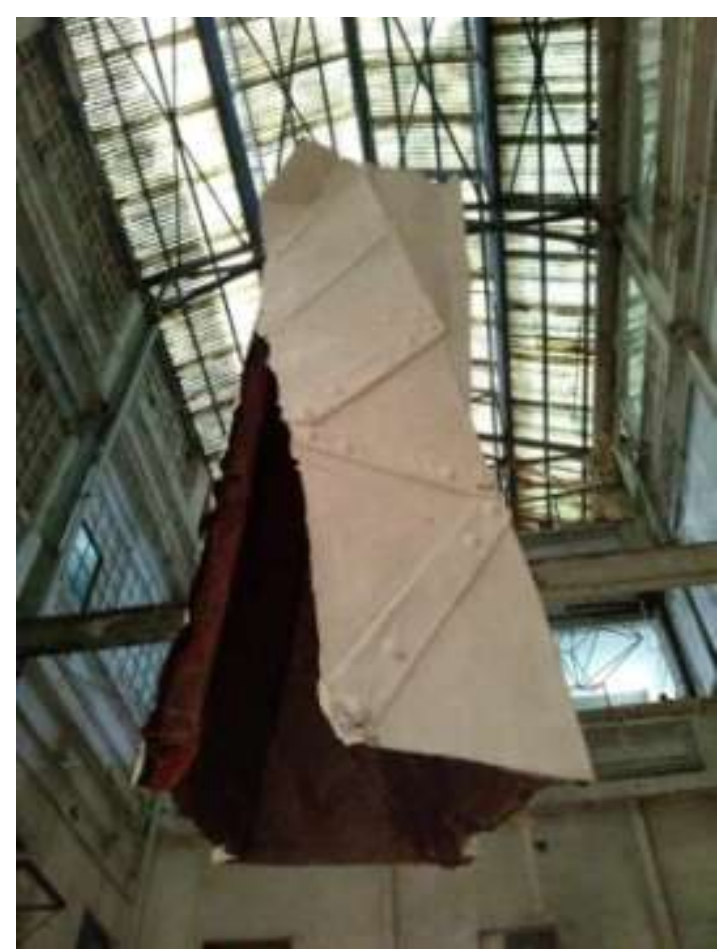

Fig. 4 - Rodrigo Torres, Monumento Maravilha, 2014

escultura

(Fonte: foto da autora)

Poiésis, Niterói, v. 19, n. 31, jan./jun. 2018. 
Muitas deles afetam uma classe social que não se beneficia das renovações além de comprometer sua integração com as diversas outras camadas da sociedade, excluindo-a e invisibilizando-a. Vistas do alto, as cidades construídas por arquitetos e urbanistas que não chegam ao rés do chão tornam-se excludentes. Entretanto, como observa Michel de Certeau (1998, p. 202), "a rua geometricamente definida por um urbanismo é transformada em espaço pelos pedestres".

Sem os relatos os novos bairros ficam desertos. Pelas histórias os novos lugares se tornam habitáveis. Habitar é narrativizar. Fomentar ou restaurar essa narratividade é, portanto, uma forma de reabilitação. Há que despertar as histórias que dormem nas ruas e que jazem às vezes em um simples nome [...] São as chaves da cidade. (CERTEAU, 1996, p. 201)

É nesse tempo-espaço do dia a dia, através das pequenas ações cotidianas que se constrói um espaço, na interrelação e por meio da cooperação mútua desses "praticantes ordinários da cidade". (CERTEAU, 1998, p. 171) Talvez seja preciso caminhar. Como ensina Labucci (2013), o caminhar é uma modalidade do pensamento, envolve uma ética, pois quem caminha jamais é isolado. Sempre se está em um contexto que nos provoca e nos leva a fazer perguntas a nós mesmos. Entrar em contato com a rua, sentindo as vibrações das calçadas, das gentes, os cheiros e sons é primordial. O caminhar como uma prática estética, que permite atravessar os espaços, construir e interpretar as paisagens urbanas que nos circundam, é o que sugere Francesco Careri (2013). Uma perspectiva de atualização política de errâncias artísticas do passado pode nos colocar em contato com o tecido urbano através de afetos ainda não experimentados por muitos. Assumir a lentidão dos corpos contra a velocidade impressa no cotidiano pela máquina é ver de outra forma, é transver realidades que surgem nas brechas. Nesse cenário iluminado por holofotes espetacularizadores é preciso buscar fissuras e frestas, nas sombras e nos afetos construídos por outras relações. Na contramão de todo esse processo de captura e de cafetinagem ${ }^{9}$ resistindo junto, re(e)xistindo através e pela arte. Faz-se necessário traçar novos percursos, abrir e descobrir caminhos que atravessem a geometrização da ordenação urbana. 


\section{Notas}

${ }^{1}$ O conceito de cidade criativa tem a economia criativa como base de seu desenvolvimento e busca "um modelo de organização urbana coerente com um paradigma socioeconômico em transição, do industrial para uma economia norteada pelo setor secundário". (REIS, 2012, p. 51) A economia criativa constitui a base do conjunto de empresas que tomam a arte, a cultura, a criatividade, o saber vivo e cotidiano como seu processo e produto final ao mesmo tempo. Este conceito surge no contexto da desmaterialização do trabalho, na conformação com uma economia da informação, do conhecimento e do aprendizado, bem como no momento em que ocorre uma dinamização de uma cultura do consumo de modos de vida alternativos ao mundo fordista e no qual os novos fatores de produção considerados são as habilidades cognitivas e comunicacionais. Após seu surgimento na Austrália, o governo britânico se inspirou nessa proposta de "colocar a criatividade no epicentro do programa estratégico do país, enfatizando sua importância para a consecução de objetivos socioeconômicos e a consequente competitividade mundial" e o então primeiro ministro Tony Blair organizou uma "força-tarefa" com fins de analisar as contas do país, as tendências globais e as vantagens competitivas nacionais. Como resultado, foram identificados 13 setores com grande potencial econômico e que foram nomeados indústrias criativas. Reis (2012, p. 25) lembra que "no jargão econômico, 'indústria' equivale a um setor econômico, não necessariamente manufatureiro. De onde se tem 'indústria financeira' ou 'indústria criativa'”. Tais indústrias são compreendidas como aquelas que "têm sua origem na criatividade, habilidade e talento individuais e que apresentam um potencial para a criação de riqueza e empregos por meio da geração e exploração de propriedade intelectual". (REIS apud Departamento de Cultura, Mídia e Esportes [DCMS] do Reino Unido, 2012, p. 25)

$2 \mathrm{Na}$ introdução do livro Trabalho Imaterial, Giuseppe Coco explica a constituição dessa nova organização do capitalismo e do trabalho imaterial: "passou-se a falar de um 'capitalismo cognitivo' capaz de capturar os processos de subjetivação para torná-los vetores de suas próprias revoluções. [...] A centralidade do trabalho imaterial diz respeito ao fato de suas atividades materiais (de manipulação e transformação da natureza) dependerem de seus elementos cognitivos, linguísticos e afetivos (de manipulação dos símbolos). Ou seja, o trabalho material passa a depender do imaterial, onde o imaterial diz respeito à subjetividade: conhecimento, comunicação, afetos. 0 capitalismo se torna cognitivo não pelo fato de mobilizar o conhecimento, mas porque passamos de uma situação na qual se produziram mercadorias por meio de conhecimento à outra, no qual o conhecimento produz, tautologicamente, conhecimento: a produção e a manipulação de símbolos torna-se a base da manipulação da natureza, até o ponto de nela determinarem-se verdadeiros processos de valorização. Nesse contexto, o capitalismo precisa se 'revolucionar' continuamente para capturar processos de subjetivação que the são cada vez mais externos, que ele não consegue mais materializar e manter dentro do chão da fábrica e de sua relação salarial”. Com formas constantemente renovadas de captura da subjetividade o capitalismo metamorfoseia-se como uma passagem de um "modo de produção" a uma "produção de mundos", o mundo das marcas, do marketing que visa "trazer para dentro do eixo da acumulação toda a variedade dos processos de subjetivação e criação". (COCO, 20113, p. 5-6)

3 Para um aprofundamento do tema, ver os textos de Geraldo Raunig e Isabell Lorey, disponíveis em Producción cultural y prácticas instituyentes Líneas de ruptura en la crítica institucional.

40 uso da palavra "ocupação" não se refere ao movimento okupa, sendo utilizada no sentido de "estar em um determinado espaço".

Poiésis, Niterói, v. 19, n. 31, jan./jun. 2018. 
5 A gentrificação, conceito criado por Ruth Glass em 1964, define os processos de desalojamento das populações dos bairros devido às remoções ou às expulsões compulsórias ou "branca", aquelas que se dão de forma mais lenta, mas são tão violentas quanto à primeira. 0 aumento do valor dos imóveis provoca o deslocamento da população para bairros onde não estão estabelecidos laços afetivos.

6 Discussões sobre as três indústrias e seus processos de transformação podem ser lidas na tese da autora, citada nas referências.

70 termo vagalume é uma referência ao texto de Didi-Huberman “A sobrevivência dos vagalumes” e está explicitado na tese supracitada.

8 SMH é uma sigla utilizada pela Prefeitura do Rio de Janeiro na marcação das casas destinadas à demolição e significa Secretaria Municipal de Habitação.

9 Em referência à Suely Rolnik em seu texto Geopolítica da Cafetinagem.

\section{Referências}

AURELI, Pier Vittorio. O regresso da fábrica: território, arquitetura, operários e capital. Trad. João Santos. Disponível em http://uninomade.net/tenda/o-regresso-da-fabrica/. (sessão Tenda). In OperaViva Magazine, Roma, 31/12/2016. Disponível em http://operaviva.info/il-ritorno-della-fabbrica/. Acesso em 1/4/2017.

BUDEN, B. et. al. Producción cultural y prácticas instituyentes Líneas de ruptura en la crítica institucional: transform. Madrid: Traficantes del Sueño/creative commons, 2008.

CARERI, Francesco. Walkscapes: o caminhar como prática estética. São Paulo: Ed. G. Gili, 2013.

CARRILLO, Jesus. Las nuevas fábricas de la cultura: los lugares de la creacion y la producción cultural en la españa contemporánea. In SANTANA, Lynda E. Avendaño (Org.). Silencio y política: aproximaciones desde el arte, la filosofía, el psicoanálisis y el procomún. Madrid: Traficantes de Sueños/UAM/UB. Disponível em https://www.traficantes.net/sites/default/files/pdfs/. Acesso em 2/3/2015.

CERTEAU, Michel. A invenção do cotidiano1. Artes de fazer. Petrópolis: Editora Vozes, 1998. Disponível em http://www.uneb.br/gestec/files/2011/10/74892255-A-Invenc-a-odo-cotidiano-Michel-de-Certeau.pdf. Acesso em 1/4/2014.

DELGADO, Manuel. La ciudad mentirosa. Fraude y miseria del modelo Barcelona. Madrid: Los Libros de la Catarata, 2007. 242 p. 
LABUCCI, Luciano. Caminhar, uma revolução. São Paulo: Martins Fontes, 2013.

LANDRY, Charles. Origens e futuros da cidade criativa. São Paulo: SESI-SP, 2013.

LAZZARATO, Maurício; NEGRI, Antonio; COCO, Giuseppe. Trabalho imaterial. Trad. Monica de Jesus Cesar. Rio de Janeiro: Lamparina, 2013.

REIS, Ana Carla Fonseca. Cidades criativas. São Paulo: SESI-SP, 2012.

SANTOS, Marilane A. A fábrica Bhering e a inserção da arte no tecido urbano: relações entre os usos dos espaços industriais e os projetos de cidade. Tese (doutorado em Arte e Cultura Contemporânea). Instituto de Artes, Universidade do Estado do Rio de Janeiro, Rio de Janeiro, 2017.

ROLNIK, Suely. Geopolítica da Cafetinagem. In Núcleo de Estudos da Subjetividade: PósGraduação em Psicologia Clínica da PUC/SP. São Paulo: PUC/SP, 2006.

SZANIECKI, Barbara; SILVA, Gerardo. Rio: dois projetos para uma cidade do conhecimento. In Outras palavras: Comunicação compartilhada e pós-capitalismo, 2010. Disponível em http://www.overmundo.com.br/overblog/rio-dois-projetos-para-uma-cidade-do-conhecimento. Acesso em 5/5/2015. 